\title{
Chemical Evaluation of the Glass Making Potentials of Silica Sand Deposits along Cross River in Cross River State, South-East of Nigeria
}

\author{
Nicholas O. Anaekwe and Yusuf M. Hassan
}

\begin{abstract}
Analytical techniques such as $\mathrm{X}$-ray Fluorescence Spectroscopy (XRF) and Atomic Absorption Spectroscopy (AAS) coupled with statistical package for multivariate analyses were used to characterize silica sand deposit obtained along Cross River in Cross River State, South Eastern Nigeria. Samples were collected from five locations along the river which include: Ikom-Okuni, Obubra-Ofumbogha, Abi-Ediba, Biase-Agwagune and Etung-Effraya. The results of analyses revealed that silicon dioxide $\left(\mathrm{SiO}_{2}\right)$ forms the predominant metal oxide in the entire samples followed by iron oxides $\left(\mathrm{Fe}_{2} \mathrm{O}_{3}\right)$, sodium oxide $\left(\mathrm{Na}_{2} \mathrm{O}\right)$. Other Oxides such as aluminum oxide (AI2O3), potassium oxide $\left(\mathrm{k}_{2} \mathrm{O}\right)$ etc were also present. Further beneficiation of the silica sand samples gave increased silica dioxide content across all the samples and increase and decrease of other metal oxides. The acid demand value (ADV) and $\mathrm{pH}$ value of the silica sand determination revealed a moderately low ADV and neutral $\mathrm{pH}$ value of all the samples. A correlation between the mean values of $\mathrm{SiO}_{2}$ and $\mathrm{Fe}_{2} \mathrm{O}_{3}$ in all the samples across all the sampling locations showed an inverse relationship between $\mathrm{SiO}_{2}$ and $\mathrm{Fe}_{2} \mathrm{O}_{3}$. Furthermore, comparison using population $\mathrm{t}$ - test of observed mean of $\mathrm{SiO}_{2}$ and $\mathrm{Fe}_{2} \mathrm{O}_{3}$, with their observed minimum standard $(90.52 \%$, $0.005 \%$ ) shows that the silica sand samples from Ediba and Agwagune can be used as a source of $\mathrm{SiO}_{2}$ for glass making due to their high $\mathrm{SiO}_{2}$ and low levels of $\mathrm{Fe}_{2} \mathrm{O}_{3}$ content.
\end{abstract}

Index Terms-Concentration; Glass making; Metal oxides; Silica sand.

\section{INTRODUCTION}

Sand is loose, disjointed mass of mineral substances in a thinly granular condition that usually contains quartz (silica), with a small proportion of feldspar, magnetite, mica, and some resistant minerals. It is resulted from mechanical chemical disintegration of rocks under the influences of abrasion and weathering [35].

According to British Geological survey [3], Silica sand is an industrial term used for sand or easily disaggregated sandstone and it contains a high proportion of silica grains (usually more than $95 \%$ of $\mathrm{SO}_{2}$ ).

Quartz is the most common silica crystal and the second most common mineral on the earth's surface. It is found in almost every type of rock (igneous, metamorphic and sedimentary). Silica occurs in nine different crystalline forms and the three main forms include quartz, which is the most common, tridymite and cristobalite. For a particular

Published on June 6, 2017.

N. O. A. is with Department of Chemical and Petroleum Engineering, Federal University, Ndufu-Alike, Ikwo, Ebonyi State, Nigeria. (e-mail: nickanaekwe@yahoo.com)

Y. M. H. is with National Agency for Food and Drug Administration and Control, (NAFDAC). Nigeria. (e-mail: yussufaluv@yahoo.com) source of silica sand to be suitable for glass making, it must not only contain a very high proportion of silica but also should not contain more than strictly limited amounts of certain metallic elements [11]. Presence of iron in silica sand makes the resulting glass to be coloured and the iron level is consequently the most critical parameter in determining whether particular sand is good for making clear or coloured glass [36].

According to [32], window glass sand may contain $0.1 \%$ to $0.5 \%$ iron oxide $\left(\mathrm{Fe}_{2} \mathrm{O}_{3}\right)$ and dark green bottle glass as much as $2 \%$ to $3 \%$ iron oxide. For colour generally, the sand may contain less than $0.035 \% \mathrm{Fe} 2 \mathrm{O} 3$, for flat glass in the range of $0.040 \%$ to $0.1 \% \mathrm{Fe}_{2} \mathrm{O}_{3}$ [3]. Reference [2], reported that, most glasses have roughly similar chemical composition of $70 \% \mathrm{SiO} 2,12 \%-16 \% \mathrm{Na}_{2} \mathrm{O}, 5 \% 1 \%-3 \%$ $\mathrm{Al}_{2} \mathrm{O}_{3}$, within these limits the composition is varied to suit particular product and production method. Grain-size distribution or grain shape is another important factor in glass making. According to [5], the grain size should lie within a given size limit and must be uniform. The ideal size of the grains should be between 0.1 and $0.5 \mathrm{~mm}$ in diameter or between 15100 mesh (BSS number) and it is required that $75 \%$ of the grain should fall within this range [7]. Grain morphology is another physical property that determines the suitability of the silica sand for glass making. According to [32], [20] the roundness of the grain must be angular rather than rounded. Reference [30] reported that, minerals with specific gravity greater than 2.65 cannot be suitable for glass making. These types of minerals exist as inclusions in a finished glass and can survive the glass melting process and come out as solid or stone defects. Glasses may be devised to meet almost any imaginable requirement for many specialized applications.

Glass can be made by melting together several minerals at very high temperature. Silica sand can be used to manufacture glass temperature about 1700 0C. The production temperature can be reduced to 800 OC by addition of soda ash $\left(\mathrm{Na}_{2} \mathrm{CO}_{3}\right)$ (2) The uses and application of glass in today's technology are numerous and therefore, this research work seeks to evaluate chemically the glass making potentials of silica sand deposits along Cross River in Cross River State, South - east of Nigeria. 


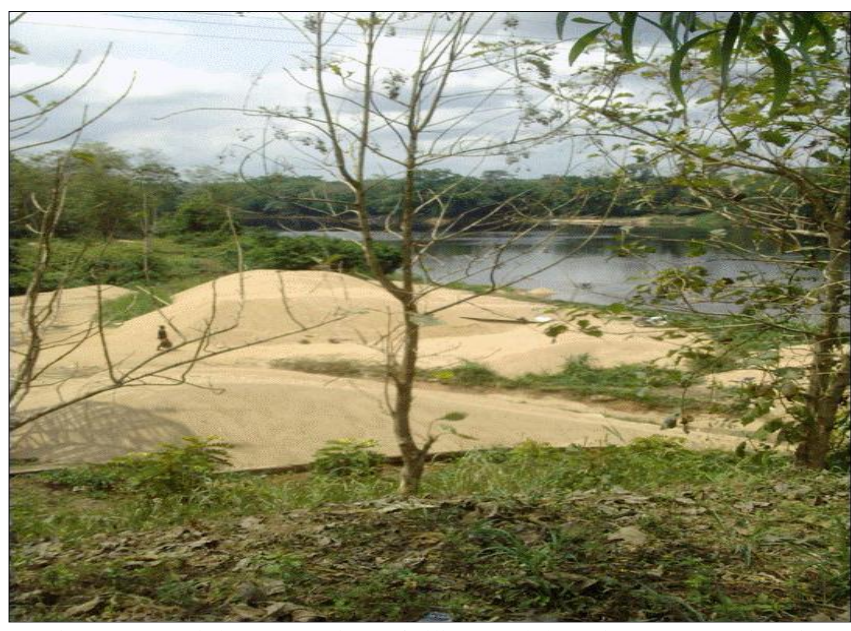

Fig. 1. An aerial outcrop view of silica sand deposit on Cross River in Cross River State, Nigeria

\section{MATERIALS AND METHODS}

\section{A. The Study Area}

The study of this research work covers the following locations along the cross river, the locations are as follows: Ikom-Okuni, Obubra-Ofumbogha, Abi-Ediba, BiaseAgwagune and Etung-Effraya as shown in the study map (Fig. 2). This river has its source from the Atlantic Ocean passing through Calabar Ugeg to Obubra. The River is mainly found in Cross River State, South Eastern Region of Nigeria [18]. Its length and size makes it one of the largest tributaries of Atlantic Ocean in Nigeria.

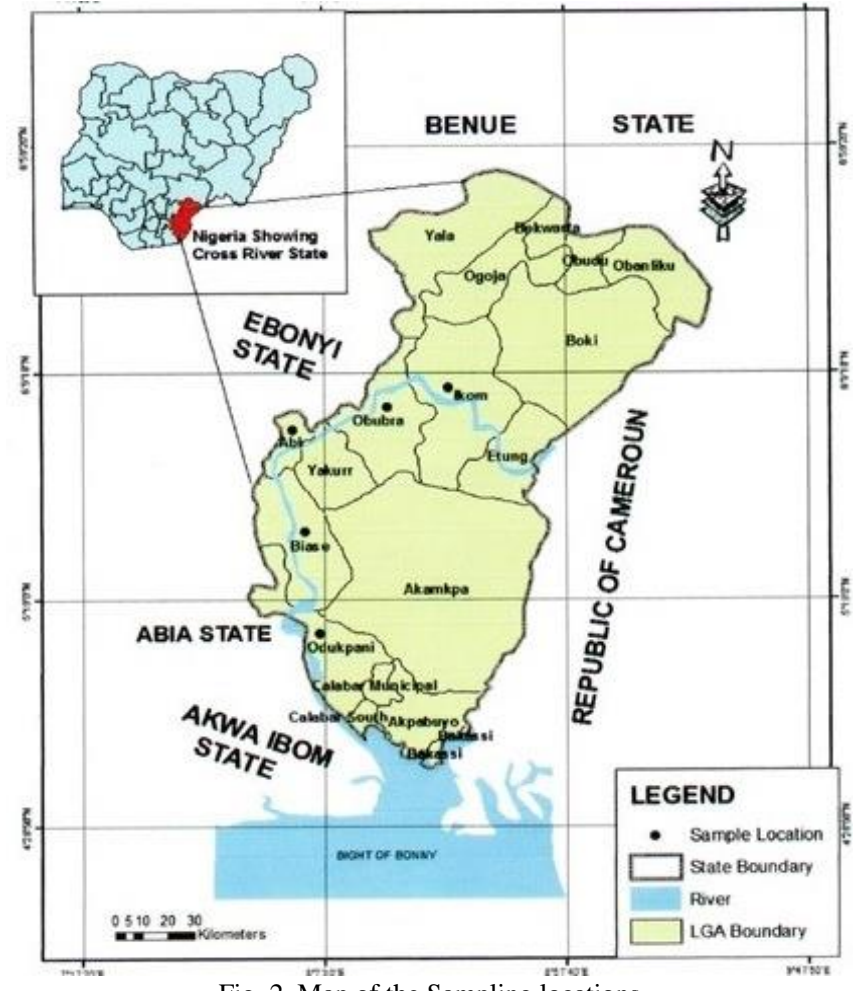

Fig. 2. Map of the Sampling locations

\section{B. Sampling}

Five silica sand samples were collected from each of the five designated sampling locations (Agwagune, Ediba,Ofumbogha, Okuni and Effraya ) on the map (fig. 2). The five samples drawn from each sampling point were thoroughly homogenized together to obtain a single composite sample representing each of the sampling points.
The composite samples collected were transferred into a clean sample bags to make a total number of five samples collected in all the sampling locations. The samples collected were taken to the laboratory for preparation and pretreatment.

\section{Sample Pretreatment and Preparation}

The collected composite samples were individually poured into a mesh screen and placed in plastic containers, scrubbed and thoroughly washed with distilled water to remove impurities.

The crushed fine grain particles were further sieved using $100 \mathrm{~mm}$ mesh screen to ensure homogeneity of particle size. The crusher and mesh were repeatedly washed and rinsed with distilled water to avoid contamination each time a new sample was to be crushed and sieved. Each of the pulverized samples was poured into a clean-dried universal bottles and set for extraction of metals in solution, while the other remaining parts of the uncrushed samples were preserved as a reference samples.

\section{Sample Digestion}

From each of the representative samples (composite samples), $0.2 \mathrm{~g}$ was weighed and placed in a clean-dried crucible and $5 \mathrm{~mL}$ mixture of nitric and perchloric acid was added in the ratio of $3: 2$, followed by $10 \mathrm{~mL}$ of hydrofluoric acid (HF) and refluxed for one hour. The mixture was then allowed to cool to room temperature and $5 \mathrm{~mL}$ of concentrated hydrochloric acid $(\mathrm{HCl})$ was added and allow to settle down, and then filtered into $100 \mathrm{~mL}$ plastic flask and made up to mark with de-ionized water. The solution is allowed to stay for three (3) days before elemental analysis was done using atomic absorption spectrophotometer (AAS) [40] and [39]. Determination of Metal Oxides Concentration

This was carried out using atomic absorption spectrophotometer (AAS), Shimadzu model AA 6800; x-ray fluorescence spectrophotometer (XRF) Mini Pal Model 4 version PW430 and UV-spectrophotometer model 2400 Hatch. The atomic absorption spectrophotometer was used for each determination of $\mathrm{MnO}, \mathrm{MgO}, \mathrm{PbO}$ and $\mathrm{K}_{2} \mathrm{O}$. Working standard solution for each element was prepared and the standard solutions and aliquots of the diluted clear digest were used for the determination. Standard curve was used to establish the relationship between absorption intensity and concentration of each element [42], [41]. The detection limit of the AAS was $<0.001 \mathrm{mg} / \mathrm{L}$. The X-Ray fluorescence spectrophotometer was used for the determine $\mathrm{SiO} 2, \mathrm{Fe}_{2} \mathrm{O}_{3}, \mathrm{CaO}, \mathrm{Al}_{2} \mathrm{O}_{3}, \mathrm{Na}_{2} \mathrm{O}, \mathrm{TiO}_{2}, \mathrm{NiO}, \mathrm{ZnO}, \mathrm{BaO}$ and $\mathrm{CuO}$. A binder was added to a specific amount of each of the pulverized samples. It was mixed and pressed in a hydraulic chamber to form a pellet. The pellet was then loaded into the Analyzer of the spectrophotometer. To produce x-rays, a voltage of $30 \mathrm{KV}$ and a current $1 \mathrm{~mA}$ was applied. The analyzer was ran for about 30-60 seconds after calibrating using the software attached to it. The result was displayed automatically on the printout. All the samples were analyzed following the same procedure [43].

\section{E. Beneficiation and Up-gradation of Samples}

The beneficiation of the silica sand samples was done according to the method of [37], [38]. 20g of the representative samples were weighed and placed in a 250 
$\mathrm{mL}$ flask and $100 \mathrm{~mL}$ of oxalic acid added. The mixture was placed on a heating plate and agitated $(870 \mathrm{rpm})$ at a temperature of $80{ }^{0} \mathrm{C}$ to $90{ }^{\circ} \mathrm{C}$ for 2 hours. To ensures uniformity; the agitation was kept constant for all the experiments. A watch glass was fitted to the flask to prevent evaporation during each experiment, the samples were filtered and the residue washed with distilled water and dried in an oven and the percentage concentration of metal oxides in each sample determined using XRF.

\section{F. Determination of Loss on Ignition (LOI) and $\mathrm{pH}$}

$10 \mathrm{~g}$ of each sample were taken and carefully poured in a clean crucible and weighed using analytical balance. The weighed samples were then placed in an electric muffle furnace and heated for 1 hour at $9500 \mathrm{C}$ to determine the loss on ignition.

The $\mathrm{pH}$ of the samples was determined electronically using a $\mathrm{pH}$ meter of $\pm 0.1 \%$ sensitivity model WTW $\mathrm{pH}$ 422. (The instrument was calibrated using a buffer solution) [40].

\section{G. Determination of Acid Demand Values of Samples}

Acid Demand Values (ADV), is a measure of soluble carbonates present in a given silica sand sample. It value determines a low or higher concentration of alkali or

TABLE I PERCENTAGE COMPOSITION OF OXIDES OF SILICA SAND DEPOSITS IN FIVE SAMPLING LOCATIONS ALONG CRosS RiveR

\begin{tabular}{|c|c|c|c|c|c|c|c|c|c|c|c|c|c|c|c|}
\hline "Locations & & & & & & & $\boldsymbol{D}_{\mathbf{x}}$ & Concen & aton? & & & & & & \\
\hline Oxides & $\mathrm{SiO}_{2}$ & $\mathrm{Fe}_{2} \mathrm{O}_{3}$ & $\mathbf{K}_{2} \mathbf{O}$ & $\mathrm{Na}_{2} \mathrm{O}$ & $\mathrm{CaO}$ & $\mathbf{A l}_{2} \mathbf{O}_{3}$ & MgO & $\mathrm{TiO}_{2}$ & $\mathrm{ZnO}$ & $\mathrm{NiO}$ & PbO & $\mathrm{BaO}$ & $\mathbf{P}_{2} \mathbf{O}_{5}$ & MnO & $\mathrm{CuO}$ \\
\hline Agwagune & 90.270 & 0.532 & 0.001 & 0.600 & 0.005 & 0.015 & 0.002 & 0.023 & 0.006 & 0.052 & 0.018 & 0.071 & 0.021 & 0.110 & 0.005 \\
\hline Ediba & 90.520 & 0.525 & 0.002 & 0.052 & 0.004 & 0.008 & 0.002 & 0.024 & 0.005 & 0.018 & 0.017 & 0.032 & 0.423 & 0.201 & 0.012 \\
\hline Effraya & 89.280 & 0.721 & 0.002 & 0.005 & 0.006 & 0.160 & 0.004 & 0.026 & 0.007 & 0.042 & 0.091 & 0.041 & 0.095 & 0.013 & 0.072 \\
\hline Ofumbogha & 89.890 & 0.634 & 0.002 & 0.005 & 0.005 & 0.016 & 0.003 & 0.021 & 0.00 & 0.160 & 0.021 & 0.038 & 0.018 & 0.012 & 0.002 \\
\hline Okunni & 89.7705 & 0.646 & 0.003 & 0.005 & 0.006 & 0.016 & 0.003 & 0.026 & 0.006 & 0.012 & 0.024 & 0.035 & 0.023 & 0.01 & 0.013 \\
\hline Total & 449.730 & 3.058 & 0.010 & 0.666 & 0.026 & 0.215 & 0.015 & 0.120 & 0.030 & 0.284 & 0.171 & 0.217 & 0.58 & 0.346 & 0.104 \\
\hline Average & 89.950 & 0.612 & 0.002 & 0.133 & 0.005 & 0.043 & 0.003 & 0.024 & 0.006 & 0.057 & 0.034 & 0.043 & 0.116 & 0.069 & 0.021 \\
\hline
\end{tabular}

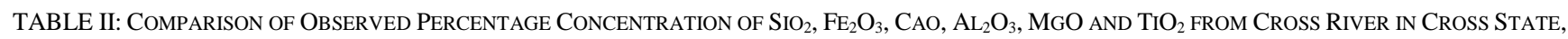
NigERIA WITH THEIR PERCENTAGE MinimuM STANDARD

\begin{tabular}{|c|c|c|c|c|c|}
\hline Metal oxides & Observe Mean (\%) & Minimun Standard (\%) & $\bar{t}$ & Mean Difference & Sig.(2 tailed) \\
\hline $\mathrm{SiO}_{2}$ & 89.950 & 95.000 & $7.961 *$ & 0.90400 & 0.001 \\
\hline $\mathrm{Fe}_{2} \mathrm{O}_{3}$ & 0.6116 & 0.0050 & $20.949 *$ & 0.380600 & 0.001 \\
\hline $\mathrm{CaO}$ & 0.0052 & 0.1000 & $-1235.25^{*}$ & 0.0988200 & 0.000 \\
\hline $\mathrm{Al}_{2} \mathrm{O}_{3}$ & 0.0430 & 0.1000 & $-968.977 *$ & -0.094940 & 0.000 \\
\hline $\mathrm{MgO}$ & 0.0029 & $0 . \mathrm{I} 000$ & $-44.680 *$ & -0.0952200 & 0.000 \\
\hline $\mathrm{TiO}_{2}$ & 0.0240 & 0.0120 & $35.857 *$ & 0.0500000 & 0.000 \\
\hline
\end{tabular}

\section{A. Acid Demand Values (ADV)}

The results of acid demand values (ADV) of the silica sand samples are presented in figure 3 . The results show the acid demand values of sand deposits highest value at Effraya (25.00) and Ediba (15.14) as the lowest. carbonates reacting materials present in given silica sand sample. Their presence is an indicator of whether given silica sand sample can be used for glass making. It is therefore important that the presence of these reacting materials be measured so that uniformity and formulation control may be achieved. The ADV was therefore carried out according to the methods as reported in previous work [28].

The metal oxide concentrations were determined using the samples collected from five (5) different locations along the River course of Cross River. The locations include: Agwagune, Ediba, Effraya, Ofumbogha and Okuni. The mean percentage metal oxide concentration of silica sand samples is presented in Table I. Comparison of observed percentage concentration of some of the oxides from Cross in Cross State, Nigeria with their percentage minimum acid demand values and $\mathrm{pH}$ of the silica sand are shown in Figs. 3 and 4. 


\section{B. Results of Determination of $p H$ Value for Silica Sand Deposits}

The results of $\mathrm{pH}$ values for the silica sand samples collected from the five different locations are shown in Fig. 4. The highest $\mathrm{pH}$ value occurred at Okuni while the lowest was at Ofumbogha.

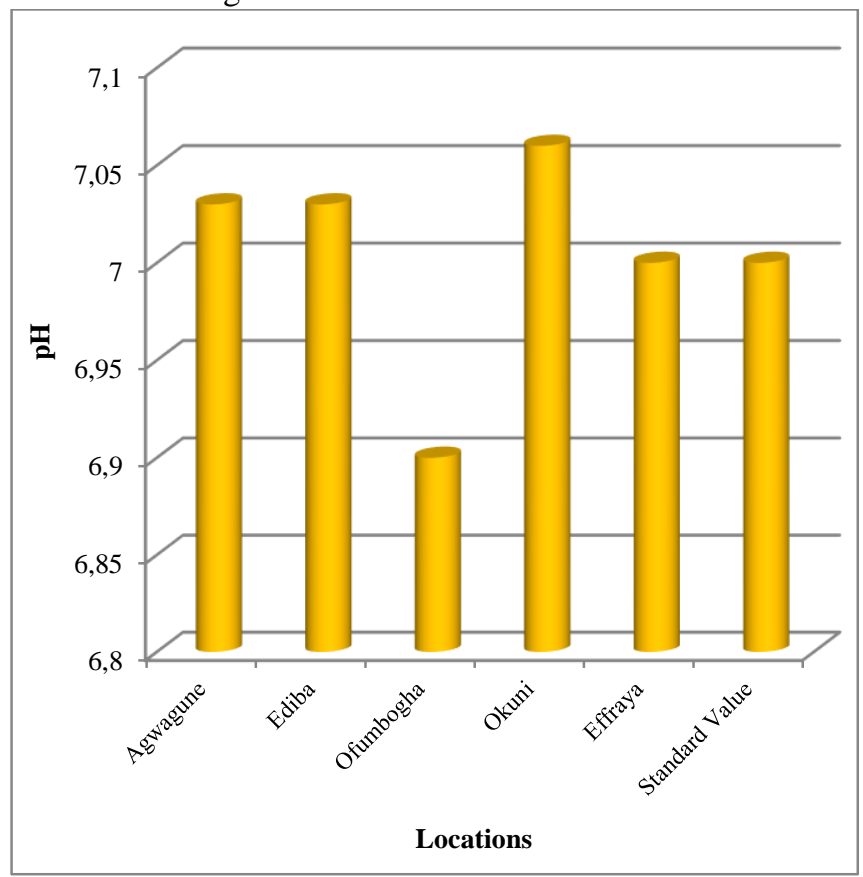

Fig. 4. $\mathrm{pH}$ of silica sand samples at different locations

\section{DISCUSSION}

The results of concentration of silica sand samples obtained from Cross River in Cross River State, Nigeria have been analyzed using some standard analytical methods. The results are as presented in Table I, Fig. 3 and 4. Comparison of concentration of some of the metal oxides and their minimum standards are presented in Table II.

\section{A. Metal Oxides Concentration}

The mean percentage of metal oxide concentration $(\mathrm{SiO} 2$, $\mathrm{Fe}_{2} \mathrm{O}_{3}, \mathrm{~K}_{2} \mathrm{O}, \mathrm{NaO}, \mathrm{CaO}, \mathrm{Al}_{2} \mathrm{O}_{3}, \mathrm{MgO}, \mathrm{TiO}_{2}, \mathrm{ZnO}, \mathrm{NiO}$, $\mathrm{PbO}, \mathrm{BaO}, \mathrm{P}_{2} \mathrm{O}_{5}, \mathrm{MnO}$, and $\mathrm{CuO}$ ) in the silica sand samples are presented in Table I. The values obtained for $\mathrm{SiO}_{2}$ across all the five samples locations: (Agwagune, Ediba, Effraya and Okunni) are within the acceptable standard of glass making. $\mathrm{SiO}_{2}$ form the major raw material in glass making when compared to that of European Commission standard [34]. This high $\mathrm{SiO}_{2}$ content trend in all the samples revealed that silica sand generally consists of high $\mathrm{SiO}_{2}$ content (quartz) which also agrees with works [1], [26]. Comparison of the observed mean values of $\mathrm{SiO}_{2}, \mathrm{Fe}_{2} \mathrm{O}_{3}$, $\mathrm{CaO}, \mathrm{Al}_{2} \mathrm{O}_{3}, \mathrm{MgO}$ and $\mathrm{TiO}_{2}$ (Table II) in the silica sand samples with their glass making standard using a population t-test revealed the concentration of $\mathrm{SiO} 2$ were acceptable while $\mathrm{CaO}, \mathrm{Al}_{2} \mathrm{O}_{3}$ and $\mathrm{MgO}$ was below the minimum standard, while those of $\mathrm{Fe}_{2} \mathrm{O}_{3}$ and $\mathrm{TiO}_{2}$ were above the minimum standard which imply that the entire silica sand sample require further beneficiation to reduce the $\mathrm{Fe}_{2} \mathrm{O}_{3}$ content to a more acceptable standard level as stipulated by the American ceramic society and the National Bureau of standards $[9 ; 15]$.

The concentration of $\mathrm{Fe}_{2} \mathrm{O}_{3}$ in any silica sand deposit determines the quality of glass to be produced. A slight increase in $\mathrm{Fe}_{2} \mathrm{O}_{3}$ content gives the glass a green, yellow or red color as a result should not exceed $0.005 \%$. This coloration to a certain extent can be neutralized by the addition of manganese resulting to a faint shade or purple color [13], [12].

Comparison of the percentage concentration of $\mathrm{SiO}_{2}$ obtained in this study with those of other authors revealed that although most of $\mathrm{SiO}_{2}$ concentrations were below minimum standard, they however fall within the range after further beneficiation was undertaken, their $\mathrm{SiO}_{2}$ content was upgraded to the minimum standard. The results revealed that the correlation between $\mathrm{SiO}_{2}$ and $\mathrm{Fe}_{2} \mathrm{O}_{3}$ is strong but positive $(\mathrm{r}=0.741)$ which implies that there is a direct relationship between $\mathrm{SiO} 2$ and $\mathrm{Fe}_{2} \mathrm{O}_{3}$ in the samples. Most high-quality glass sand can exceed $99.5 \% \quad \mathrm{SiO} 2$ when processed and would average close to the $99.80 \%$ level. However, silica content in the sand is not the problem; rather, it is that fraction which is not silica which include clays and a host of minerals which contribute Iron, Aluminum, Titanium, Calcium, Magnesium and various trace constituents. Any constituent in the silica sand other than silica is therefore considered as a contaminant, principal of which is iron, aluminum, and titanium [6].

The results of concentration of iron oxide from the five locations sampled (Agwagune, Ediba, Effraya and Okunni) showed that the values obtained from all the locations are too high when compared with the minimum standard for glass making while that of potassium are too low (Table II). Therefore, silica sands obtained from all the locations (Agwagune, Ediba, Effraya and Okunni) cannot be used for glass making directly without reduction of its $\mathrm{Fe}_{2} \mathrm{O}_{3}$ and addition of $\mathrm{K}_{2} \mathrm{O}$ since both oxides are important for glass production. $\mathrm{K}_{2} \mathrm{O}$ in glass making process bring about transparency [19].

From Table I, the results of $\mathrm{Na}_{2} \mathrm{O}$ obtained from the five locations showed that only the value obtained from Agwagune (0.600) can be used to produce optical glass when compared with the European Commission minimum standard. While those obtained from Ediba, Effraya, Ofumbogha and Okunni cannot be used to produce glass, since their $\mathrm{Na} 2 \mathrm{O}$ values are below the standard for glass making [19]. Also the results of $\mathrm{CaO}$ from all the locations can only be used in production of panel glass since their values falls within the acceptable limit of 0.32 . Calcium oxide plays a crucial role in glass manufacturing process by increasing the stability weathering properties and lowering the viscosity of glass.

$\mathrm{Al}_{2} \mathrm{O}_{3}$ values from Table I were below the minimum standard for glass making, therefore there is need to upgrade the values to a more acceptable value for glass production. $\mathrm{Al}_{2} \mathrm{O}_{3}$ when introduced in glass production stiffens the glass melt and at the same time lower the coefficient of thermal expansion resulting to high thermal shock resistance with improve durability [14].

The results of the analysis from all the locations revealed that $\mathrm{MgO}$ are within the acceptable limit for production of panel glass and glass ceramic. $\mathrm{MgO}$ enhances stability of glass and lowers the viscosity of the glass melt [29], [23].

All the results obtained cannot be used for the production of glass because the values of $\mathrm{TiO}_{2}$ and $\mathrm{P}_{2} \mathrm{O}_{5}$ are below the 
minimum standard for glass making (Table $\mathrm{I}$ ). $\mathrm{TiO}_{2}$ act as colorant in the glass production [17]. Phosphorous peroxide is added to glass in form of phosphoric acid, calcium phosphate or boric ash to increase the transparency of the glass product but it however reduces the mechanical properties instead [27], [23].

The result showed that $\mathrm{PbO}$ obtained from all the locations were below the minimum standard for glass making, but the values obtained from all the locations were above the minimum standard for the production of water glass (Table I). Lead oxide $(\mathrm{PbO})$ is introduced in to glass batch as red lead $\left(\mathrm{Pb}_{3} \mathrm{O}_{4}\right)$ or as litharge $(\mathrm{PbO})$ which imparts a perfect transparency, brightness and a high refractive index to the glass thereby facilitating its clean cutting. Studies have shown that lead oxide has the ability to refract light transmitted through it more than any other glass making material [19]. For $\mathrm{BaO}$, the concentration according to Table I is only good for production of optical glass. $\mathrm{BaO}$ is introduced as barium carbonate in glass batch $(\mathrm{BaCO} 3)$; it increases the specific weight, refractive index and sonority of glass [14].

The oxides such as Zinc Oxide $(\mathrm{ZnO})$, Nikel Oxide $(\mathrm{NiO})$, Manganese Dioxide $(\mathrm{MnO})$ and Copper Oxide $(\mathrm{CuO})$ were also present in the samples collected. $\mathrm{ZnO}$ when introduced in glass production make the glass to be resistance to thermal shock improves it mechanical and chemical properties Nikel oxide is strong absorber of light and very expansive decoglurant. When $\mathrm{MnO}$ is introduced in glass as the mineral pyrolusite, oxygen is evolved which oxidized the ferrous silicate to ferric silicate; The manganese (iii) oxide which first formed imparts a violet coloration to the glass which is complementary to the yellow hue of the ferric silicate and the mass therefore appears as colorless, $\mathrm{MnO}$ is therefore a decoglurant in glass making [23]. $\mathrm{CuO}$ is introduced as a colorant to shade of red colors.

\section{B. Acid demand values ( $A D V)$}

The mean values of the acid demand values (ADV) of the silica sand samples are presented in Fig. 3. The result revealed that the highest Acid Demand Value is obtained from Effraya and the least is the one from Ediba. This result is similar to those obtained by other researchers [24;33]. The acid demand values measure the amount of alkaline materials that should not be present in already processed washed and classified silica sand. ADV range from 1 to a maximum of 50, a low ADV (near zero) is an indication of either no acid was consumed and so virtually no soluble carbonates are present in the sample or low alkaline materials in the samples while a high ADV is an indication of nearly all acid added in the test was consumed or a high soluble carbonate and salts that can be deleterious in the application of the silica sand for glass making. This low ADV may be attributed to the leaching and removal of soluble carbonate minerals (primarily calcite) by downward percolating oxidizing surface waters [28].

\section{Loss on ignition and $\mathrm{pH}$}

The $\mathrm{pH}$ of the silica sand samples is presented in Fig. 4. The mean results of the samples from the five locations revealed the $\mathrm{pH}$ value to be 7.00 . The $\mathrm{pH}$ of a given sample gives the water soluble level of alkalinity or acidity of the silica sand [25]. A higher or lower $\mathrm{pH}$ values signify the presence of acidic or basic oxide in given silica sand sample. Sand with a $\mathrm{pH}$ close to neutral (7.00) is therefore the best for glass making [8].

\section{REFERENCES}

[1] T. Bajah. Chemistry science teachers association of Nigeria (STAN). Ibadan: Heinemann, 1986, pp. 78-89.

[2] BGMC "British Glass Manufacturers Confederation, 9 Churchill Way" Chapeltown, Sheffield, South Yorkshire, 5352PY.uk. www.britglass.org.uk/typesglass.

[3] BGS "British Geological survey, silica sand supply Chain.UK" (September 2011). Available: www.mineralszone.com/ minerals/silica.html.

[4] H.L. Bourne. Glass raw materials. In D. D. Carr (Eds.), Industrial minerals and rocks. Littleton, CO: Society for Mining, Metallurgy, and Exploration, pp. 543-650,

[5] BS2975 "British Standard Methods for sampling and analysis of Glass making sands"

[6] H.G. Charles. Modern glass manufacturing. New York: Starling Press, 1974, pp. 45-76

[7] M.I. David.(Ju;y, 2011). "A study of silica sand quality and end uses in Surrey and Kent" Available: www.Istglass.Istthings.com/articles/glasscolouring.html.

[8] R.H. Doremus Glass science. New York: John Wiley, 1973, pp. 78 90.

[9] G.A. Enuvie. and J.O. Etu-Efeotor. (2003). The occurrence and economic potential of clean sand deposits of the Niger Delta. Journal of African Earth Science, 6 (1), 2003, pp. 61-65.

[10] T.D. Frank and M.D.Douglas, (April , 1972). Advance in glass making,Available:

2010fromhttp://www.Chass.Utoranto.Callhistory/material/glass.html

[11] R. George. (August,2011)"Substances used in the making of coloured glass" Avaailable:www.britglass.org.uk/history-glass.

[12] H.B. Goldman. Glass raw materials. In D. D. Carr (Eds.), Industrial minerals and rocks. Littleton: Society for Mining, Metallurgy, and Exploration, 1994, pp. 869-877.

[13] Horst, S. Glass - nature, structure and properties. London: Springer, 1991, pp. 5-17.

[14] K. Hrdina. Production and properties of ULE glass with regards to EUV Masks, proceeding at the International Workshop on extreme ultra-violet lithography, corning, New York, 1999.

[15] F.S. James and H.D. Robert. Ceramic and glass material: Structure, properties and processing. London: Springer, 2008, pp.158

[16] K.B. Ketner. Silica sand. In D. A. Brobst and W. P. Pratt (Eds.), United States mineral resources professional paper 820. Washinton, DC: U.S. Geological Survey, 1973, pp.577-580.

[17] P. Marson. Glass. New York: The HamLyn, 1978, pp. 12-55,

[18] R.A. Etiuma, and N.O. Anaekwe.(May,2015). Ambient air sulphur (iv) oxide concentration monitoring in the suburb of a large commercial city in the South Eastern Nigeria. International journal of scientific \& technology research. ISSN 2277-8616. Available: www.ijstr.org

[19] G.W. Morey and N.I. Bowen. The binary system sodium meta silicate-silica. Journal of Physical Chemistry, 1970, vol. 28, pp. 1167-1179. 1970

[20] M. C. A. Powers. New roundness scale for sedimentary particles. John Willey and Sons Inc., New York. 1983.

[21] [21]. Raw Materials Research and Development Council (RMRDC), Federal Ministry of Science and Technology, Multi - Disciplinary Task Force - report of the Techno-Economy Survey on NonMetallic Mineral Products Sector, 3rd Update Abuja, Nigeria. 1991, Pp $14-15$ and 49 .

[22] H. Rawson. Inorganic glass forming systems. London: Academic Press, 1967, pp.41-76.

[23] M.B. Robert, C.R. Jeffry. and M. William. Suitability of the pine formation as a glass, 2002.

[24] N. Sell. Industrial pollution, control issues and techniques. New York: Van Nostrand Reinhold, 1981, pp.118-143.

[25] R.B. Sosman. The properties of silica. London: Rein Holding, 1954 pp. 7-11.

[26] E. Stocchi. Industrial chemistry. New York: Wiley, 1975, pp. $117-$ 125 .

[27] S. P. Sundeen. Geologic study of sand deposits in the state of Michigan-Phase I. Michigan: Institute of Mineral Research,1978, pp. 1-7.

[28] H. Thomas. Glas making. New York: The corning Museum of Glass, 2001, pp. 56-77. 
[29] F.V. Tooley. Hand Book of Glass manufacturing. 2nd Edition, Ogden Press, New York, 1989.

[30] F.A. Ushie, E. Esu, E. and G.J. Udom. A preliminary evaluation of Otamiri River sands for the production of plain glass. Journal of Applied Science and Environmental Management, 2005, 9 (1), 65-68.

[31] J.E. Waudby.(2011). "A summary of the known deposit of Glass in Nigeria” Available:www.fao.org/decrep/005/ac6726/ac672b/6.htm.

[32] McLaws. Uses and specification of silica sand. Research Council of Alberta Report, 64 A, 1971, pp. 71-74.

[33] European Commission (2001) Integrated Pollution Prevention and Control (IPPC) Reference Document on Best Available Techniques in the Glass Manufacturing Industry. Available:www.prtres.ss/data/images/vidrio052A143B3A73F757.pdf.

[34] W.A. Redmond. "Sand." Microsoft Encarta 2009, Microsoft Corporation, 2008.

[35] S. A. Kamar. What is Silica? EBS 425 - Mineral Perindustrian. 2004.

[36] F. Veglio, B. Passariello and C. Abbruzzese. Iron removal process for high-purity silica sand production by oxalic acid leaching. Industrial and Engineering Chemical Research,1999, 38, 4443-4448.

[37] I.I. Tarasova, A.W. L. Dudeney \& S. Pilurzu. Glass sand processing by oxalic acid leaching and photo catalytic effluent treatment Minerals Engineering, 2001, 14, pp.639-646.

[38] S. A. Sinex, A.Y. Cantillo \& G. R. Helz. Accuracy of acid extraction methods for trace metals in sediments. Analytical Chemistry, 52 (14), pp.2342-2346. 1980.

[39] P. Harries. Association of official analytic chemistry handbook. England: Philip Harries Holding, 1975, pp.85-105.

[40] W.O. Emufurieta, A.A. Kayode \& S.A. Coker. Mineralogy, geochemistry and economic evaluation of kaolin deposit near Ubulu Uku, Awo- Omana and Buan in Southern Nigeria. Journal of Mineralogy and Geology, 1992, 28, pp. $210-281$.

[41] D.C. Boyd, P.S. Danielson, D.A. Thompson \& K. Kirk-Othmer. Encyclopedia of chemical technology (vol. 12, 4th ed.). New York: Wiley \& Sons, pp. 45-53, 1994.

[42] S.P. Malu \&G.A. Bassey. Periwinkle (T. fuscatus) shell as alternative source of lime for glass industry. Global Journal of Pure and Applied Sciences, 9 (4), 2003, pp. $491-494$.

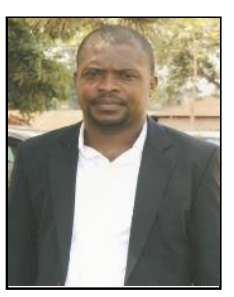

Nicholas Ogbonna Anaekwe was born on 5th May, 1980 at Aba, South Eastern Nigeria.Nicholas obtained a Bachelor of Science degree in Applied Chemistry in 2010 and a Master of Science degree in Analytical Chemistry in 2014 from prestigious University of Calabar, Calabar, Cross River State, Nigeria. $\mathrm{He}$ is currently pursuing a $\mathrm{PhD}$ degree programme on Impact of solid waste on ground water, soil quality and determination of energy content of solid waste from Aba dumpsite (an aspect of Environmental/Analytical Chemistry) in University of Calabar.

$\mathrm{He}$ is currently working as a LECTURER at Department of Chemical and Petroleum Engineering, Faculty of Engineering and Technology, Federal University, Ndufu-Alike, Ikwo (FUNAI), Ebony State, Nigeria. He has worked as a QUALITY CONTROL ANALYST with De Ultimate Paint at No 12 Aba-Port Harcourt Express way, Aba, Abia, Nigeria from 2012 to 2013. He has completed some research works in Environmental pollution and analysis of food items. He has published one research paper titled Ambient air sulphur(iv) oxide concentration monitoring in the suburb of a large commercial city in the South Eastern Nigeria in International Journal of Scientific \& Technology Research whereas his second paper 'Determination of ambient air Sulphur(iv) oxide concentration in the commercial city of Aba, Nigeria has been accepted for publication in International Journal of Development and Sustainability. His research interests are in Quality control analysis and Environmental pollution monitoring.

Mr. Anaekwe has received award of Excellency from Students' Chemical Society of Nigeria, University of Calabar as one of their outstanding past Presidents and is Member of FUNAI Course Evaluation Committee. He is happily married to Mrs. Bertha Anaekwe (nee Nkwocha) an Environmental Chemist.

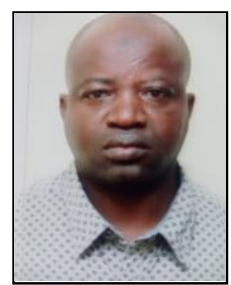

Mr Hassan Yusuf M. was born on 24th December, 1970 at Jega, North West Nigeria. Hassan obtained a higher National Diploma (HND) in Science Laboratory Technology (Applied Chemistry option) in 1997 at Federal Polytechnic Kaura Namoda, Zamfara State. He later proceeded to Bayero University, Kano for his Postgraduate Diploma in Chemistry and obtained a degree in 2008. Later in 2016, he obtained his Masters degree in Analytical Chemistry at University of Calabar, Cross River

State.

$\mathrm{He}$ is a member of Institute of Chartered Chemist of Nigeria and also an Associate member of Nigeria Institute of Laboratory Technologist. He served under the Ministry of Education, Kebbi State from year 2000-2009 as Chemistry teacher. He later joined National Agency for Food and Drug Administration and Control (NAFDAC) as Senior Laboratory Technologist from 2009-2013.

$\mathrm{He}$ is currently Assistant Chief Laboratory Technologist. He is happily married and blessed with three children. 